TINJAUAN STRATEGI MENCIPTAKAN KEPUASAN

PELANGGAN

PADA PT. SANPRIMA SENTOSA

TUGAS AKHIR

Oleh:

BUDIYANTO

NPM : 012011017

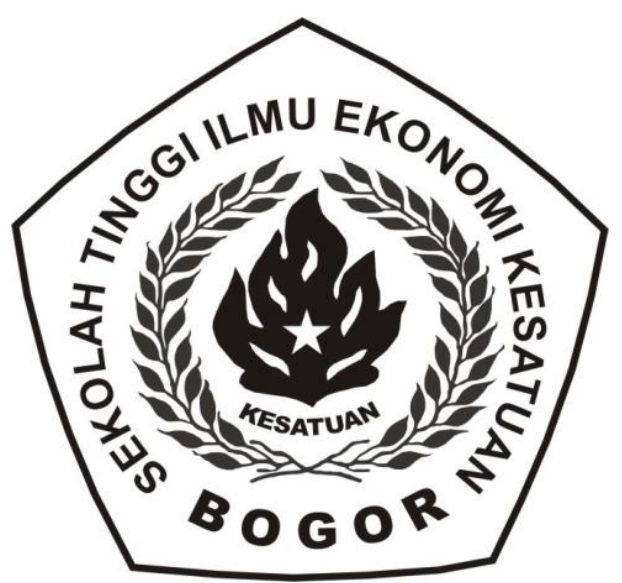

PROGRAM DIPLOMA III MANAJEMEN PEMASARAN

SEKOLAH TINGGI ILMU EKONOMI KESATUAN

BOGOR

2014 


\section{TINJAUAN STRATEGI MENCIPTAKAN KEPUASAN PELANGGAN \\ PADA PT. SANPRIMA SENTOSA}

\section{Tugas Akhir}

sebagai salah satu syarat untuk memperoleh

gelar Ahli Madya pada Program Studi Manajemen Pemasaran

Sekolah Tinggi IImu Ekonomi Kesatuan

Oleh:

BUDIYANTO

NPM : 012011017

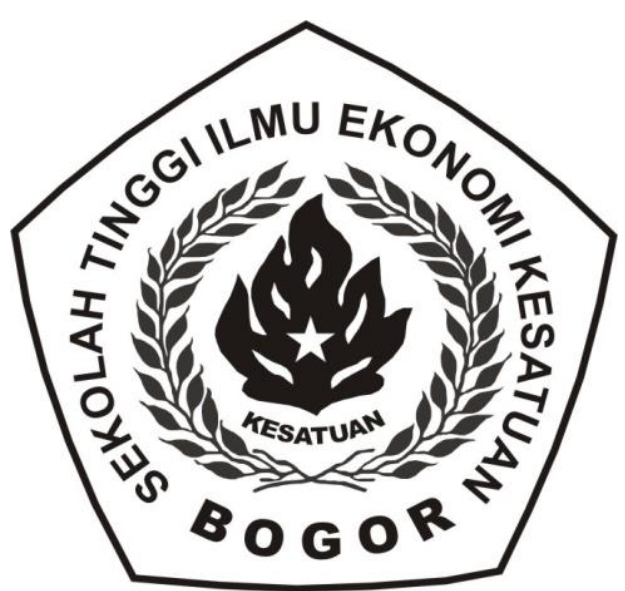

PROGRAM DIPLOMA III MANAJEMEN PEMASARAN SEKOLAH TINGGI ILMU EKONOMI KESATUAN BOGOR 


\title{
TINJAUAN STRATEGI MENCIPTAKAN KEPUASAN PELANGGAN \\ PADA PT. SANPRIMA SENTOSA
}

\author{
TUGAS AKHIR
}

Telah diujikan dan disetujui pada sidang ahli madya

Sekolah Tinggi IImu Ekonomi Kesatuan pada,

$\begin{array}{ll}\text { Hari } & : \text { Kamis } \\ \text { Tanggal } & : 21 \text { Agustus } 2014\end{array}$

Mengetahui,

Ketua STIE Kesatuan

$$
\begin{gathered}
\text { Ketua Program Studi } \\
\text { Manajemen Pemasaran }
\end{gathered}
$$

Nusa Muktiadji, Ir., MM. Angga Sulistiono, SE., MM. 


\title{
TINJAUAN STRATEGI MENCIPTAKAN KEPUASAN PELANGGAN \\ PADA PT. SANPRIMA SENTOSA
}

\author{
TUGAS AKHIR
}

Telah disetujui oleh Pembimbing

Angga Sulistiono, SE., MM.

Telah diujikan dan disetujui pada sidang Ahli Madya dan

Dinyatakan LULUS pada tanggal

Seperti tertera di bawah ini

Bogor, 21 Agustus 2014

$\begin{array}{ll}\text { Penguji I Penguji II } & \text { P }\end{array}$

Mumuh Mulyana, SE., MM., M.Si $\quad$ Dr. Hj. Yulia Nurendah, SE., MM 


\begin{abstract}
ABSTRAK
BUDIYANTO. NPM : 012011017. Tinjauan Strategi Menciptakan Kepuasan Pelanggan Pada PT. Sanprima Sentosa. Di bawah bimbingan ANGGA SULISTIONO.

Kepuasan pelanggan adalah suatu keadaan dimana keinginan, harapan, dan kebutuhan pelanggan terpenuhi dengan ditandai terbentuknya perasaan puas, senang, dan kelegaan seseorang dikarenakan mengkonsumsi suatu produk atau jasa setelah membandingkan antara harapan dan kenyataan dalam menggunakan suatu barang atau jasa serta menikmati pelayanan yang diberikan oleh barang atau jasa tersebut.

Tujuan penulis dalam penelitian ini adalah untuk mengetahui bagaimana upaya yang dilakukan PT. Sanprima Sentosa dalam memuaskan pelanggannya, layanan seperti apa yang diberikan oleh PT. Sanprima Sentosa dalam memuaskan pelanggannya dan hambatan-hambatan apa saja yang dihadapi oleh PT. Sanprima Sentosa dalam upaya memuaskan pelanggannya. Penulis melakukan peninjauan dan pengamatan pada suatu perusahaan yang bergerak dibidang otomotif yaitu dealer sepada motor Honda.

Demikian halnya PT. Sanprima Sentosa selaku dealer resmi sepeda motor bermerek Honda tempat penulis melakukan penelitian terus berusaha melakukan dan memberikan pelayanan yang maksimal dan terbaik sehingga para konsumennya terpuaskan dan menjadi seorang pelanggan yang loyal.
\end{abstract}

Kata kunci : Kepuasan Pelanggan 


\section{KATA PENGANTAR}

Segala puji dan syukur penulis panjatkan kehadirat Tuhan YESUS KRISTUS, atas segala hikmat, kasih, dan karunia-NYA sehingga penulis dapat menyelesaikan tugas akhir yang berjudul "Tinjauan Strategi Menciptakan Kepuasan Pelanggan pada PT. Sanprima Sentosa" dapat terselesaikan dengan baik.

Pada kesempatan ini secara khusus penulis berterima kasih kepada pihak-pihak yang telah membantu penulis dalam proses penyusunan tugas akhir ini sehingga dapat terselesaikan dengan baik, yaitu kepada:

1. Bapak Nusa Muktiadji, Ir., MM. Selaku Ketua Sekolah Tinggi IImu Ekonomi Kesatuan Bogor.

2. Bapak Angga Sulistiono, SE., MM selaku Ketua Program Studi Manajemen Pemasaran D-3 dan dosen pembimbing tugas akhir di Sekolah Tinggi Ilmu Ekonomi Kesatuan Bogor yang telah banyak meluangkan waktu, tenaga, dan pikirannya untuk memberikan bimbingan dan pengarahan yang bermanfaat dalam penyusunan penulisan tugas akhir ini.

3. Bapak Mumuh Mulyana, SE., MM., M.Si dan Ibu Dr. Hj. Yulia Nurendah, SE., MM selaku penguji dalam sidang tugas akhir ini.

4. Pa Adi Nurmauludi sebagai supervisor penulis di PT Sanprima Sentosa terima kasih buat segala pembelajarannya selama ini kepada penulis.

5. Pa Sastra Wijaya sebagai koordinator penulis di PT Sanprima Sentosa terima kasih buat segala pembelajarannya selama ini kepada penulis.

6. Dani, Eduard, dan Yohanes teman-teman Marketing Executive penulis di PT. Sanprima Sentosa terimakasih buat segala dukungannya semua.

7. Ko Chandra teman seperjuangan penulis di dalam mencari Konsumen yang tidak pernah lelah nganvas bareng.

8. Tjhung Kim Goan dan Lauw Giok Lian selaku baba dan mama penulis yang selalu memberikan dukungan dan doa yang tidak pernah putusputusnya yang selalu diberikan kepada penulis sehingga penulis dapat menyelesaikan tugas akhir ini.

9. Yanuar selaku koko penulis terima kasih atas segala dukungan, pengertian serta doa yang tidak pernah putus-putusnya yang selalu diberikan kepada penulis. 
10. Helena Ginting yang selalu memberikan semangat dan dukungannya kepada penulis untuk terus bisa menyelesaikan tugas akhir ini, terima kasih atas semangat dan dukungannya kepada penulis.

11. Astrella Angela yang selalu memberikan semangat dan dukungannya kepada penulis untuk terus bisa menyelesaikan tugas akhir ini, terima kasih atas semangat dan dukungannya kepada penulis.

12. Bapa Johanes Ferdinan De Poere, S.Pak yang selalu memberikan semangat dan motivasinya kepada penulis untuk bisa menyelesaikan tugas akhir ini. Tuhan YESUS Memberkati.

13. Ci Tenny, Ko Billy, Bian, Fanny, Pa Tafsir serta anak-anak yang bimbingan belajar di Seven Smart Study yang tidak bisa penulis sebutkan satu-satu terima kasih atas segala dukungan kalian untuk penulis sehingga dapat menyelesaikan tugas akhir ini.

14. Mas Medi Herlambang terima kasih buat segala pembelajaran dan informasi yang bermanfaat bagi penulis dalam penyusun tugas akhir ini.

15. Teman-teman penulis di kampus, Geng Tokek Pohon, Angga, Rendy, Erick, Peter, Patrick, dan Chandra S. terimakasih atas doa dan dukungannya, kalian gokil semua.

16. Teman-teman penulis selama 2 tahun di KCM, Erick, Gempita, Yustine, Peter, Patrick, Chandra H., Chandra S., dan Nico terimakasih atas doa dan dukungannya, kalian adalah keluarga kedua penulis.

17. Teman-teman penulis para pengurus KCM yang baru terimakasih atas doa dan dukungannya

18. Teman-teman mahasiswa Manajemen Pemasaran D-3 di Sekolah Tinggi IImu Ekonomi Kesatuan Bogor.

Akhir kata, penulis berharap semoga tujuan pembuatan tugas akhir ini dapat tercapai dengan yang diharapkan. Mungkin dalam penyusunan tugas akhir ini terdapat beberapa kekurangan yang disengaja ataupun yang tidak disengaja. Semoga tugas akhir ini bermanfaat bagi para pembaca dan mampu menambah wawasan untuk pengetahuan bersama.

Bogor, Juni 2014 


\section{DAFTAR ISI}

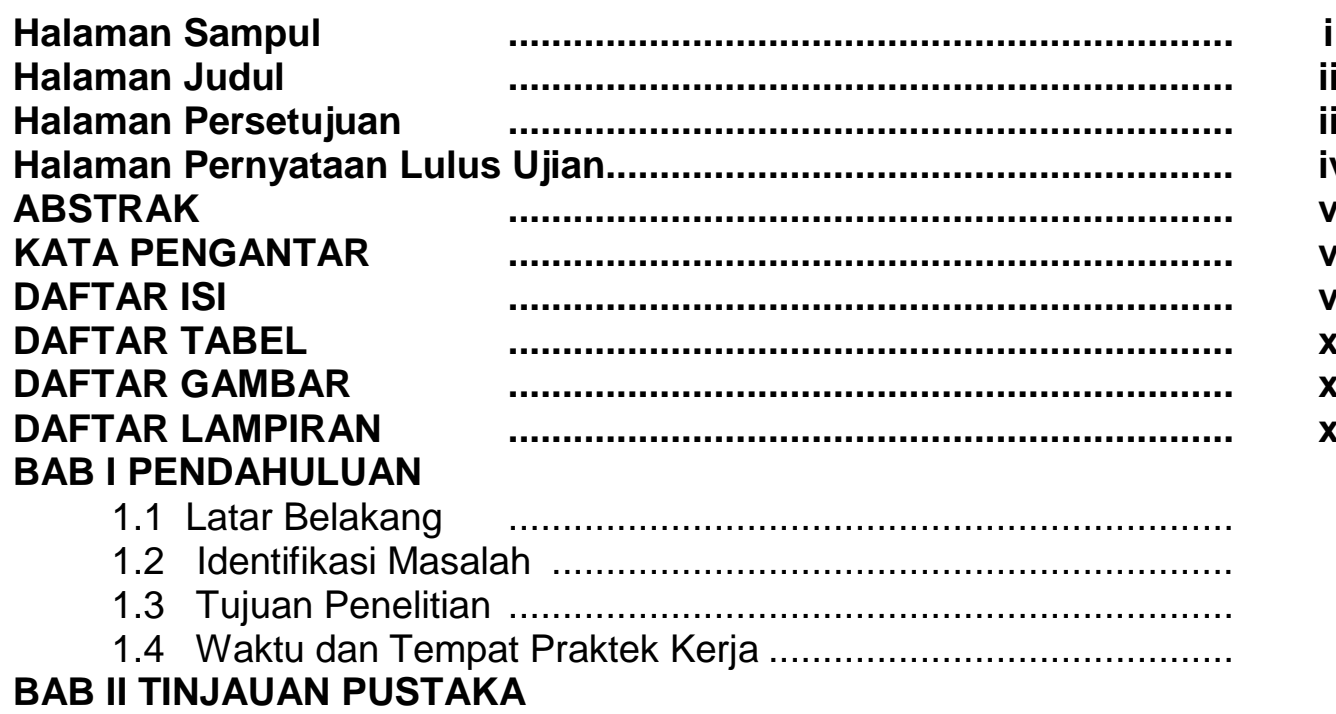

2.1 Definisi Pemasaran............................................................... 5

2.2 Definisi Manajemen Pemasaran ........................................... 6

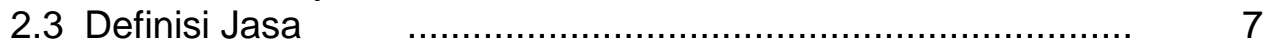

2.3.1 Bauran Pemasaran Jasa........................................... 8

2.3.2 Kategori Bauran Jasa ............................................. $\quad 11$

2.3.3 Karakteristik Jasa .................................................. 12

2.3.4 Klasifikasi Jasa ................................................... 16

2.3.5 Dimensi Jasa ........................................................... 16

2.4 Strategi Pemasaran untuk Perusahaan Jasa .......................... 17

2.4.1 Rantai Laba-Jasa................................................. 19

2.5 Definisi Perilaku Konsumen .............................................. 19

2.6 Definisi Kepuasan ...................................................... 20

2.7 Definisi Pelanggan .............................................................. 21

2.8 Definisi Kepuasan Pelanggan ............................................... 22

2.9 Faktor Utama Dalam Menentukan Kepuasan Pelanggan ........ 23

2.10 Metode Pengukuran Kepuasan Pelanggan............................ 24

2.11 Manfaat Pengukuran Kepuasan Pelanggan ......................... 25

2.12 Ciri-ciri Pelanggan yang Puas............................................. 26

2.13 Manajemen Hubungan Pelanggan..................................... 27

2.14 Analisis SWOT ......................................................... 27

\section{BAB III HASIL DAN PEMBAHASAN}

3.1 Sejarah Perusahaan .......................................................... 29

3.1.1 Visi dan Misi Perusahaan........................................ $\quad 30$

3.1.2 Logo Perusahaan...................................................... $\quad 31$

3.2 Struktur Organisasi dan Uraian Tugas ................................ 33

3.3 Sumber Daya Manusia ..................................................... $\quad 40$

3.4 Sarana dan Prasarana ..................................................... 41

3.5 Uraian Singkat Praktek Kerja .............................................. 47

3.6 Konsumen PT. Sanprima Sentosa yang Merasa Puas dan Menjadi Loyal $\quad$........................................................... 48

3.7 Perbandingan antara Teori dan Praktek .............................. 48 3.7.1 Upaya PT. Sanprima Sentosa dalam memuaskan pelanggannya 
3.7.2 Layanan yang diberikan oleh PT. Sanprima Sentosa dalam memuaskan pelanggannya

3.7.3 Hambatan yang dihadapi oleh PT. Sanprima Sentosa dalam upaya memuaskan pelanggannya

\section{BAB IV SIMPULAN DAN SARAN}

4.1 Simpulan

4.2 Saran

62

DAFTAR PUSTAKA

64

DAFTAR LAMPIRAN 


\section{DAFTAR TABEL}

No.

Teks

Halaman

3.1 Jajaran direksi PT. Sanprima Sentosa ........................................... 29

3.2 Produk yang dijual PT. Sanprima Sentosa.................................. 33

3.3 Jumlah Karyawan PT. Sanprima Sentosa................................... 40

3.4 Tingkat Pendidikan Karyawan PT. Sanprima Sentosa .................. 40 


\section{DAFTAR GAMBAR}

No. Teks Halaman

$2.1 \quad$ Empat karakteristik jasa......................................................... 15

2.2 Tiga jenis pemasaran jasa ................................................ 18

2.3 Analisis SWOT ................................................................. 28

3.1 Logo PT. Sanprima Sentosa ............................................... 31

3.2 Produk Sepeda Motor Honda yang Dijual ................................ 32

3.3 Struktur Organisasi PT. Sanprima Sentosa .............................. 35

3.4 Sarana dan Prasarana PT. Sanprima Sentosa ........................... 44

3.5 Bagian Eksterior PT. Sanprima Sentosa.................................. 45

3.6 Bagian Interior PT. Sanprima Sentosa.................................... 46 


\section{DAFTAR LAMPIRAN}

No.

Teks

Halaman

1. Surat Keterangan Kerja

65

2. Surat Pemesanan Kendaraan (SPK) ........................................... 66

3. Angsuran Motor pada ADIRA Finance ......................................... 67

4. Angsuran Motor pada HD Finance ............................................... 68

5. Angsuran Motor pada WOM Finance .............................................. 69

6. Angsuran Motor pada OTO Finance .............................................. 70

7. Angsuran Motor pada Mega Central Finance ................................... 71

8. Angsuran Motor pada CS Finace ................................................... 74

9. Katalog Motor New Supra X 125 CW FI........................................ 75

10. Katalog Motor New Revo FI ...................................................... 77

11. Katalog Motor Beat CW FI ....................................................... 79

12. Katalog Motor New Vario 110 CW FI ............................................ 81

13. Katalog Motor Vario Techno 125 CBS MMC FI............................... 83

14. Katalog Motor Vario Techno 125 CBS ISS FI................................... 85

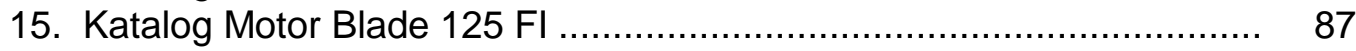

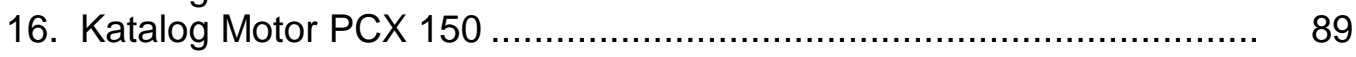

17. Katalog Motor CB 150 R Streat Fire FI..................................... 91

18. Katalog Motor Mega Pro $150 \mathrm{FI}$................................................... 93

19. Surat Serah Terima STNK .......................................................... 95

20. Surat PO / Persetujuan Pembiayaan Kredit Sepada Motor .................... 99 


\section{BAB IV \\ SIMPULAN DAN SARAN}

\subsection{Simpulan}

Di tengah persaingan yang sangat ketat, PT. Sanprima Sentosa selalu melakukan pelayanan yang prima kepada para pelanggannya sehingga banyak para pelanggannya yang merasa puas karena pelayanan yang diberikan kepadanya dengan sepenuh hati.

1. Upaya yang dilakukan PT. Sanprima Sentosa dalam memuaskan para pelanggannya dilakukan secara maksimal dan dapat memuaskan para pelanggannya. PT. Sanprima Sentosa mampu menjaga para pelanggannya yaitu dengan cara:

a. Selalu menjaga kualitas dari suatu produk yang dijualnya agar selalu berkualitas ketika sampai ditangan para pelanggannya nanti.

b. Selalu memeberikan pelayanan yang prima kepada seluruh pelangggannya sehingga dalam pelayanan tersebut para pelanggan mendapatkan hasil dari harapan dan kinerja yang diberikan dalam suatu pelayanan.

c. Selalu menjaga harga unit sepada motor Honda agar selalu stabil dan tidak terlalu melambung tinggi dari harga sebelumnya sehingga hal inilah yang membuat para pelanggan yang sensitive terhadap harga menjadi tetap setia dan selalu loyal terhadap perusahaan

d. Selalu menjaga hubungan baik antara para pelanggannya dalam komunitas kendaraan sepada motor tertentu dengan perusahaan dan selalu mengerti, mendengarkan dan empati terhadap apapun yang komunitas ini alami tentang permaslahan sepada motornya sehingga komunitas ini tidak akan berpaling kepada dealer lain.

e. Selalu mengusahakan dan menciptakan kemudahan dalam proses kredit sepada motor Honda di PT. Sanprima Sentosa.

2. Dalam melakukan pelayanannya PT. Sanprima Sentosa selalu mengedepankan pelayanan yang prima yang berdasarkan kepada prinsip 3A : Attitude (sikap) yang baik, memeberikan Attention (perhatian) yang tidak terbagi, dan juga Action (tindakan) yang konkrit atau nyata dalam memberikan suatu pelayanan yang baik guna memuaskan para 
pelanggannya karena dengan melakukan pelayanan yang prima dan berkesan di hati para pelanggannya PT. Sanprima Sentosa sampai sekarang mampu menjadi salah satu dealer caring.

3. Dalam mengahadapi hambatan-hambatan yang dihadapi PT. Sanprima Sentosa mampu menghadapinya dan juga mampu menemukan jalan keluar atau solusi yang terbaik agar selalu dapat memuaskan para pelanggannya dan selalu belajar dari kesalahan yang sudah pernah terjadi sehingga kesalahan yang sama tidak akan terulang lagi atau bisa diminimalisir.

\subsection{Saran}

Saran yang penulis akan sampaikan ketika penulis melakukan penelitian di PT.

Sanprima Sentosa yang terkait dengan penelitian ini adalah sebagai berikut ;

1. PT. Sanprima Sentosa harus lebih berupaya lagi menjadi dealer nomor satu se-Jawa Barat dalam hal memuaskan para pelanggannya dengan lebih lagi meningkatkan kualitas produknya, kualitas pelayannanya serta biaya dan kemudahan bagi para pelanggannya untuk mendapatkan produk yang dijual perusahaan.

2. PT. Sanprima Sentosa harus lebih lagi menjalin hubungan yang baik dengan para mitra kerjanya atau leasing yang akan membiayayai kredit sepada motor Honda para pelanggannya sehingga proses pengajuan pembiayaan kedit sepada motor Honda di PT. Sanprima Sentosa lebih mudah dan tidak rumit.

3. PT. Sanprima Sentosa harus lebih memperhatikan karayawannya yang akan dipromosikan menjadi seorang pemimpin (Koordinator atau supervisor marketing) agar dapat memimpin dan memberikan pembelajaran yang baru kepada para bawahannya apabila terjadi suatu permasalahan dilapangan.

4. PT. Sanprima Sentosa harus lebih lagi mendengarkan, menyimak, dan empati kepada para pelanggannya dalam menyampaikan kritik dan saran yang membangun serta menyampaikan keluhannya kepada perusahaan sehingga hal tersebut tidak akan terulang lagi dan apabila hal ini dilakukakan denagn baik maka akan banyak pelanggan yang merasa puas terhadap perusahaan dan menjadi pelanggan yang loyal. 
5. Dengan segala prestasi yang telah dicapai oleh PT. Sanprima Sentosa, maka PT. Sanprima Sentosa mampu mempertahankan prestasi tersebut dengan berbagai macam cara yang positif dan membangun perusahaaan salah satunya adalah meningkatkan kualitas pelayanannya sehingga menciptakan pelanggan-pelanggan yang loyal terhadap perusahaan. 


\section{DAFTAR PUSTAKA}

Alma, H. Buchari, 2005, Manajemen Pemasaran dan Pemasaran Jasa, Cetakan Ketujuh, Edisi Revisi, CV. Alfabeta, Bandung.

Djaslim Saladin, 2007, Intisari Pemasaran dan Unsur-unsur Pemasaran, Cetakkan Keempat, Penerbit Linda Karya, Bandung.

Gerson, Richard F., 2004, Mengukur Kepuasan Pelanggan, Penerjemah Hesty Widyaningrum, Edisi 3, PPM, Jakarta.

Irawan, Handi, 2006, 10 Prinsip Kepuasan Pelanggan, Cetakan Ketujuh, Elex Media Komputindo, Jakarta

Kurtz, David L., 2008, Principles Of Countemporary Marketing, Nelson Education LTD, Canada.

Kotler, Philip, 2004, Manajemen Pemasaran, Edisi Millennium I, PT. Indeks Kelompok Gramedia, Jakarta. Jakarta.

,2007, Manajemen Pemasaran. Edisi Kedua Belas, Indeks,

, 2008, Manajemen Pemasaran. Terjemahan Hemdra Teguh, Edisi Kedua Belas, Cetakan Kedua, Prenhalindo, Jakarta. dan Gary Armstrong, 2008, Prinsip-prinsip Pemasaran, Edisi Kedua Belas, Jilid Kesatu, Penerbit Erlangga, Jakarta.

dan Kevin Lane Keller, 2009, Manajemen Pemasaran. Edisi Ketiga Belas, Jilid Kesatu, Penerbit Erlangga, Jakarta.

Ketiga Belas, Jilid Kedua, Penerbit Erlangga, Jakarta.

Lovelock, Christopher. H dan Wright, Lauren. K, 2005, Manajemen Pemasaran Jasa, Indeks, Jakarta

Lupiyoadi, Rambat dan A, Hamdani, 2008, Manajemen Pemasaran Jasa, Salemba Empat, Jakarta.

Rangkuti, Freddy, 2006, Measuring Customer Satisfaction, Gramedia Pustaka Utama, Jakarta

2008, Analisa SWOT Teknik Membedah Kasus Busnis, Cetakan Kelima Belas, Gramedia Pustaka Utama, Jakarta.

Setiadi, Nugroho J., 2008, Perilaku Organisasi: Analisis, Perencanaan, Pelaksanaan, dan Pengendalian, Linda Karya, Bandung.

Swastha, Basu dan Irawan, 2005, Manajemen Pemasaran Modern, Penerbit Liberty, Yogyakarta.

Tjiptono, Fandy, 2004, Manajemen Pemasaran Jasa, Andy Offset, Yogyakarta. , 2005, Manajemen Pemasaran Jasa, Andy Offset, Yogyakarta. , 2006, Manajemen Pemasaran Jasa, Andy Offset, Yogyakarta. 2007, Strategi Pemasaran dan Pemasaran Jasa, Edisi Pertama, Andy Offset, Yogyakarta. dan Chandra, G., 2011, Service, Quality \& Statisfaction, Andy Offset, Yogyakarta.

Walker C, Orville and John W Mullins, 2010, Marketing Management : A Strategic Decision-Making Approach $7^{\text {th }}$ Edition, The McGraw Hill Companies, New York USA.

Yazid, 2005, Pemasarn Jasa; Konsep dan Implikasi, Edisi Kedua, Ekonisia, Fakultas Ekonomi UII, Yogyakarta.

Mulyana, M. and Sulistiono, S., 2012. Kewirausahaan: The Long Life Way of Business. 
Sulistiono, A., 2012. Analisis Pengaruh Iklan Televisi Terhadap Keputusan Pembelian Motor Yamaha Jupiter MX. Jurnal IImiah Kesatuan (JIK), 14(1).

Purba, J.H., 2001. Model Ekonometrika Kelapa Sawit Indonesia, Analisis Simulasi Kebijakan Internal dan Eksternal. Jurnal Kopertis Wilayah, 4, p.12.

Munawar, A. and Purba, J.H.V., 2006. Kajian Dampak Pelatihan terhadap Kinerja Karyawan. Jurnal Ilmiah Kesatuan Nomor, 8(7), p.2.

Munawar, A., 2012. Struktur Kapital Perusahaan Perkebunan di Indonesia, Kebijakan, Faktor-Faktor yang Mempengaruhi dan Dampaknya Terhadap Kinerja Perusahaan (Doctoral dissertation, Institut Pertanian Bogor).

Munawar, A., Sanim, B., Manurung, A.H. and Achsani, N.A., 2011. PENGUJIAN PECKING ORDER PADA PERUSAHAAN PERKEBUNAN DI INDONESIA. Jurnal Ilmiah Ranggagading, 11(2).

Nurendah, Y. and Mulyana, M., 2012. Analisis Strategi Lokasi Ritel Dan Citra Toko Giant Botani Square Bogor. Jurnal IImiah Kesatuan, 14(1), pp.21-32.

Zuhdi, S. and Yudi, D., 2008. ANALISIS BRAND LOYALTY TERHADAP KEPUTUSAN PEMBELIAN Studi Kasus Pengguna Mobil Merek TOYOTA Pada PT. Setiajaya Mobilindo Bogor. Jurnal Ilmiah Kesatuan Nomor, 10(97), p.2.

Pamungkas, B., 2005. Pengaruh Kualitas Peraturan Perundangundangan, Akuntansi Keuangan Sektor Publik, dan Penerapan Pengawasan terhadap Kualitas Laporan Keuangan Pemerintah dan Akuntabilitas Kinerja Instansi Pemerintah. Disertasi UNPAD. Bandung. Tidak Dipublikasikan.

Djanegara, M.S. and Ivonia, L., 2006. Evaluasi Pengendalian Intern Penjualan Kredit Dalam Meningkatkan Kolektibilitas Piutang pada PT Austindo Nusantara Jaya Finance. Jurnal Umum.

Sujana, S. and Sim, C.E., 2012. Pengaruh Karakteristik Individu Dan Faktor Psikologis Terhadap Keputusan Pembelian Konsumen Pada Produk Blackberry. Jurnal IImiah Ranggagading (JIR), 12(2), pp.148156.

Sujana, S., Zuhdi, S. and Kamaludin, K., 2006. Formulasi Strategi Pengembangan Jaringan Distribusi terhadap Tingkat Volume Penjualan: Studi Kasus pada PT Hero Supermarket. Jurnal Ilmiah Ranggagading (JIR), 6(2), pp.104-109.

Sujana, S., 2001. Analisis Antrian Pada Teller: Study Kasus Pada Bank Rakyat Indonesia (BRI) Bogor. Jurnal IImiah Ranggagading (JIR) Nomor, 1(2), pp.61-69. 